Rev. Elev. Méd. vét. Pays trop., 1971, 24 (1) : 19-21

\title{
Note sur les premiers cas de charbon symptomatique à Madagascar
}

\author{
par J. M. BLANCOU $\left({ }^{*}\right)$, J. RAKOTOARIVELO (**), H. SERRES (*)
}

\section{RESUME}

L'agent du charbon symptomatique Clostridium chauvoei a été isolé pour la première fois à Madagascar en août 1969. Il s'agissait des premiers cas d'une grave épizootie qui a envahi la presque totalité de l'île en quelques mois, entraînant une mortalité très importante dans les troupeaux infectés. Les souches isolées sont classiques pour tous leurs caractères. L'origine de l'épizootie est inconnue. Une anaculture totale a été préparée à partir des souches isolées soit sur milieu V.F., soit sur milieu au Thioglycollate: elle possède un pouvoir protecteur satisfaisant.

\section{INTRODUCTION}

Le charbon symptomatique est classiquement répandu sur tous les continents (3). En zone intertropicale, seules quelques îles sont considérées jusqu'ici comme totalement indemnes, en particulier Madagascar, La Réunion, Maurice, Guadeloupe (1). A Madagascar toutefois, TISSIE et RAKOTO (H.) ont suspecté la maladie en 1907 à Vohilena et 1911 à Tsinjoarivo (2), mais sans pouvoir s'en assurer. RANDRIAMBELOMA (J.B.) et BUCK (G.) suspectent également la maladie chez un bovin abattu à Tananarive en 1938, mais l'anaérobie isolé ne peut être identifié avec certitude (Communication personnelle).

Ce n'est qu'en 1969 que les premiers cas d'une forme classique de la maladie ont été constatés et que l'isolement de l'agent causal a été réalisé au Laboratoire Central de l'Elevage de Tananarive.

(*) Microbiologistes à l'I.E.M.V.T. - Laboratoire central de l'Elevage, Tananarive.

(**) Direction du Service de l'Elevage de Madagascar (Services Vétérinaires)

\section{ETUDE EPIZOOTOLOGIQUE}

\section{SYMPTOMES - LESIONS}

Les symptômes de la maladie sont absolument classiques. Peut-être peut-on noter une prédominance des formes suraiguës (viscérales). Lors de l'apparition de la maladie en région indemne, elles entraînent la mort en quelques heures.

Les lésions sont celles habituellement décrites dans la maladie : pseudo-tumeurs musculaires, infiltrées de gaz, entourées d'un odème envahissant, lésions septicémiques.

\section{EVOLUTION DE LA MALADIE A L'INTERIEUR DES FOYERS}

Une fois le foyer déclaré, l'évolution de la maladie est extrêmement rapide : les troupeaux sont atteints les uns après les autres, avec un taux de morbidité et mortalité élevé à l'intérieur de chaque troupeau.

Les chiffres, relevés dans plusieurs foyers de différentes régions de l'Ile, illustrent cette sévérité de l'infection (Tableau I).

Les taux moyens de morbidité et de mortalité apparaissent donc comme très variables 
TABLEAU $N^{\circ} \mathrm{I}$

\begin{tabular}{|c|c|c|c|c|c|}
\hline $\begin{array}{l}\text { Région } \\
\text { gêograph1que }\end{array}$ & $\begin{array}{l}\text { Effectif total } \\
\text { des foyers }\end{array}$ & $\begin{array}{l}\text { Nombre de } \\
\text { malades }\end{array}$ & $\begin{array}{l}\text { Nombre de } \\
\text { morts }\end{array}$ & $\begin{array}{l}\text { Taux de } \\
\text { morbiditê }\end{array}$ & $\begin{array}{l}\text { Taux de } \\
\text { mortalité }\end{array}$ \\
\hline Nord & 937 & 140 & 133 & $15 \mathrm{p} \cdot 100$ & 14 p. 100 \\
\hline Centre & 1.237 & 125 & 118 & $10 \mathrm{p} \cdot 100$ & 9,5 p. 100 \\
\hline Sud & 21.125 & 7.260 & 6.935 & $34 \mathrm{p}, 100$ & p. 100 \\
\hline
\end{tabular}

selon les régions : les foyers du Sud de l'Ile ont été les plus graves du fait du mode d'élevage, de la saison sèche (faiblesse physiologique des animaux) et de l'ignorance des éleveurs devant cette maladie nouvelle: plus de 50.000 mortalités ont été déclarées en moins de 3 mois dans l'ensemble des foyers.

\section{EVOLUTION DE LA MALADIE DANS L'ILE}

L'évolution de la maladie a été très rapide, affectant l'allure d'une épizootie et non celle d'une enzootie telle qu'elle est décrite classiquement en pays infectés de longue date. Cela tient probablement à l'absence d'immunité naturelle acquise au cours d'infections antérieures (5).

Les principales régions d'élevage ont été atteintes en moins d'un an, les deux foyers extrêmes étant distants de près de $1.500 \mathrm{~km}$. La date des diagnostics effectués au Laboratoire indique bien la rapidité de la contagion :

25 août 1969 : Betroka (Sud de l'Ile)

28 nov. 1969: Faratsiho (Haut plat. central)

10 janv. 1970 : Manja (Côte Sud-Ouest)

11 mars 1970: Tsaratanana (Nord)

17 mars 1970: Maintirano (Côte N.-Ouest) 13 août 1970: Ambilobe (Extrême Nord).

L'Ile des Comores, située au nord-ouest de l'Ile de Madagascar, a été atteinte en juin 1970 .

D'autre part la maladie, en milieu tropical, est considérée habituellement comme une affection de saison des pluies: or les premiers foyers sont apparus, à Madagascar, au cour de la saison sèche.

Enfin l'origine de la maladie reste inexpliquée. S'agit-il d'une maladie "dormante " dont l'agent causal aurait acquis une soudaine viru- lence par passages successifs sur des sujets affaiblis ? S'agit-il, comme nous tendons plutôt à le croire, de spores véhiculées par des rapaces migrateurs du continent africain (2) ? Les rapaces indigènes (en particulier Corvus albus et Milvus migrans) ont également très probablement contribué à l'extension de la maladie dans l'Ile.

\section{ETUDE BACTERIOLOGIQUE}

\section{ISOLEMENT DES SOUCHES}

18 souches ont été isolées, soit par inoculation directe au cobaye d'un broyat de produits suspects (tumeur, fragment d'organe, moelle osseuse), soit par inoculation d'une culture de ce broyat en bouillon V.F. glucosé ou "Thioglycollate Fluid Medium " (DIFCO). La bactérie est réisolée, par hémoculture, à partir des cobayes ayant succombé avec des lésions caractéristiques.

\section{ETUDE BACTERIOLOGIQUE}

\section{Caractères morphologiques, métaboliques, pathogènes}

Les souches isolées présentent les caractères morphologiques habituellement décrits.

La plupart ont une thermorésistance faible et ne fermentent pas le lévulose, les autres caractères étant classiques par ailleurs.

Le pouvoir pathogène est élevé à l'isolement, $0,1 \mathrm{ml}$ d'une culture fraîche tuant le cobaye en moins de 12 heures.

\section{Caractères antigéniques}

Toutes les souches présentent des caractères antigéniques communs entre elles, ainsi qu'avec une souche africaine (souche THIES) (*) après étude de l'immunité croisée. 
Leur pouvoir immunogène est satisfaisant : une anaculture formolée préparée à partir, soit d'un milieu V.F. glucosé, soit de "Thioglycollate Fluid Medium " (DIFCO). Ces deux anacultures protègent 60 à 70 p. 100 de cobayes (après une injection de $1,5 \mathrm{ml}$ ) ou 100 p. 100 (après une injection de rappel) contre l'inoculation intramusculaire de $1 \mathrm{ml}$ de culture fraîche. Huit millions de doses vaccinales ont été utilisées à ce jour pour protéger le cheptel malgache sans qu'il ait été rapporté de défaillance de la protection vaccinale.

(*) Nous remercions vivement notre confrère P. PERREAU qui a bien voulu nous adresser cette souche.

\section{SUMMARY}

Note on the first outbreak of black-quarter in Madagascar

Clostridium chauvoei has been recovered for the first time in Madagascar (in August 1969) from the first cases of a serious epizootic which spread over almost the whole island in a few months, with high mortality rates among the infested cattle. The strains recovered have classical features. The source of the disease is unknown. A formol culture has been prepared by growing the strains either on meat-liver broth or on Thioglycollate fluid-medium : it proved satisfactory.

\section{RESUMEN}

Nota sobre los primeros casos de carbunco sintomático en Madagascar

Se aisló el germen Clostridium chauvoei del carbunco sintomático por primera vez en Madagascar en agosto de 1969. Se trataba de los primeros casos de una epizootia grave que ha invadido la casi totalidad de la Isla a los algunos meses, al provocar una mortalidad muy importante en los ganados infectados. Todos los caracteres de las cepas aisladas son clásicos. Es desconocida la origen de la epizootia. Se preparó un anacultivo total a partir de cepas aisladas sea sobre medio V.F. ya sea sobre medio con thioglicolato: posee un poder protector satisfactorio.

\section{BIBLIOGRAPHIE}

1. CURASSON (G.), «Traité de Pathologie exotique vétérinaire et comparée ». T. II. 2e éd. Paris, Vıgot frères, 1942.

2. DORST (J.), * Les migrations des oiseaux », Paris. Payot, 1950.

3. I.E.M.V.T., Laboratoire Central de l'Elevage à Tananarive, « Rapports annuels », (Archives de l'I.E.M.V.T., Tananarive).

4. KATITCH (R.V.), "Les maladies des animaux domestiques causées par les microbes anaérobies », Paris, Vigot frères, 1965.

5. KATITCH (R.V.), «L'immunité naturellement acquise contre les infections provoquées par les microbes anaérobies clostridiales et sa valeur pratique », Rev. Immunol., Paris, 1964, 28 (6) : 349 56.

6. PREVOT (A.R.), TURPIN (A.), KAISER (P.) "Les bactéries anaérobies", Paris, Dunod, 1967.

7. STABLEFORTH (A.W.), GALLOWAY (I.A.), "Infectious diseases of animals », Vol. 1. London, Butterworths Scientific Publ., 1959.

8. TISSIE. RAKOTO (H.), «L'élevage à Madagascar », Bull. économ. Madagascar, $1923,2 \mathrm{e}$ trimestre : 25 . 